\title{
RESOLVED MYSTERY OF DIFFICULT NEONATAL RESUSCITATION
}

\author{
D. Manikyamba ${ }^{1}$, N. Madhavi² , I. V. Padmavathi' ${ }^{3}$ A. Krishna Prasad
}

\section{HOW TO CITE THIS ARTICLE:}

D. Manikyamba, N. Madhavi, I. V. Padmavathi, A. Krishna Prasad. "Resolved Mystery of Difficult Neonatal Resuscitation". Journal of Evolution of Medical and Dental Sciences2015; Vol.4, Issue 12, February 09;

Page: 2067-2071, DOI: 10.14260/jemds/2015/296

\begin{abstract}
Most common cause of bradycardia in newborn is sinus bradycardia due to hypoxia and acidosis. Complete Congenital Heart block (CCHB)is a rare cause of neonatal bradycardia. We are here with reporting a rare case of NLE, which presented with birth asphyxia and bradycardia, not responding to resuscitation. The baby had CHB with cardiogenic shock and was initially stabilized and sent for pediatric cardiac center for pacemaker implantation.
\end{abstract}

KEYWORDS: Complete congenital heart block, Systemic lupus erythematosus, Neonatal Lupus Erythematosus.

INTRODUCTION: Most common cause of bradycardia in newborn is sinus bradycardia due to hypoxia and acidosis. Complete Congenital Heart block (CCHB) is a rare cause of neonatal bradycardia with incidence of 1:20,000 live births. ${ }^{1} 90 \%$ of CHB are the result of transplacental passage of maternal auto antibodies causing Neonatal Lupus Erythematous (NLE). 50\% of mothers with SLE are asymptomatic and CHB in fetus or new born may be the presenting feature. ${ }^{2}$ We are here with reporting a rare case of NLE, which presented with birth asphyxia and bradycardia, not responding to resuscitation.

CASE SCENARIO: A 22 year old primigravida mother presented to labour room at 37 weeks of gestation in view of decreased fetal movements. Fetal distress was suspected because of fetal brady cardia and baby was delivered immediately by induction.

Baby had birth asphyxia and was resuscitated according to NRP guidelines. Respiratory rate and Spo 2 improved with positive pressure ventilation but the heart rate (HR) was persistently low ranging from 40 - 50 beats per minute (BPM) and circulatory status did not improve. Two doses of $0.1 \mathrm{ml}$ of 1: 10,000 IV adrenaline and normal saline bolus were given and ionotropic support was started. Inspite of all these measures, bradycardia persisted. Bed side ECG showed second degree heart block (Fig. 1) and ECHO revealed mild pericardial effusion with structurally normal heart. At this stage, diagnosis of CHB with CCF and cardiogenic shock was considered and managed on those lines. Child improved within $24 \mathrm{hrs}$. On day two, ECG showed progression of heart block from $2^{\text {nd }}$ to $3^{\text {rd }}$ degree (Fig: 2) and pericardial effusion subsided. On examination there were no skin lesions. Haemogram and liver function tests were normal. NLE being the commonest cause of CHB, we evaluated the mother for any signs and symptoms of SLE and serum for ANA were sent. Mother was asymptomatic and ANA were positive. After initial stabilization, the baby was sent to pediatric cardiology center for pacemaker implantation.

DISCUSSION: Neonatal bradycardia is defined as HR less than 100 BPM. Most common cause of neonatal bradycardia is sinus bradycardia due to acidosis and hypoxia. $2^{\text {nd }}$ and $3^{\text {rd }}$ degree CHB can present with fetal or neonatal bradycardia. $90 \%$ of CHB are due to NLE. The risk of CHB in the fetus is 


\section{CASE REPORT}

about $1-2 \%$ if the mother is anti-SSA/Ro positive and the risk increases to $5 \%$ if anti-SSB/La antibodies are also present. ${ }^{3,4}$ The recurrence rate for CHB is $15-18 \%$ in those women who had a previously affected child ${ }^{2}$. CHB is an autoimmune disease that usually develops between 16-24 weeks of gestation due to transfer of maternal IgG antibodies. Fetal tissue damage has been shown to be mediated by anti-Ro and anti-La. The target antigens of anti-Ro and anti-La are sequestrated intracellularly and found in fetal cardiac tissue. These antibodies induce myocarditis which leads to CHB by destroying the cardiac conduction system at the AV node and bundle of His. In less than $10 \%$ of cases, congenital AV block is first and second degree at birth, and $50 \%$ of these cases progress to third degree heart block as seen in the present case ${ }^{5}$. Clinical manifestations of NLE involve cardiac, dermatological, hepatic, hematologic and nervous systems, of which coetaneous manifestations are the most common. The most clinically significant manifestations of NLE are cardiac, specifically CHB. Non cardiac manifestations of NLE usually resolve within few months coincident within the clearance of the maternal antibodies from child's circulation. NLE may cause isolated CHB or associated with endocardial fibroelastosis, long QT syndrome and cardiomyopathy ${ }^{6}$. Fetal heart rate is an important indicator of the prognosis of the disease during the neonatal period. Incidental detection of fetal bradycardia in the antenatal period should warrant screening of the mother for ANA to rule out asymptomatic SLE in mother.

Women with positive anti-Ro/anti-La antibodies should be followed during antenatal period beginning at 16 weeks of gestation for the development of heart block in the fetus by serial echocardiography to monitor for prolonged mechanical PR interval [Mechanical PR interval is defined as the time interval from the onset of the mitral A wave( atrial systole) to the onset of the aortic pulsed Doppler tracing(ventricular systole) within the same left ventricular cardiac cycle by using gated- pulsed Doppler technique].As the congenital HB progresses rapidly from first degree to complete HB and cardiomyopathy with hydrops fetalis and in utero fetal loss, early detection of first degree HB by mechanical PR interval can help in starting antenatal therapy thus preventing further progression of cardiac damage. Once third degree HB is identified, it is irreversible despite of therapy with dexamethasone one or IVIG. ${ }^{7}$

For fetuses with CCHB, Biophysical profile (BPP) score alone is not a good indicator of fetal wellbeing. The 'non stress test' of BPP which shows fetal heart rate variability in the absence of uterine contractions, believed to be an indicator of fetal distress cannot be utilized in fetuses with CHB, as ventricular rate in CHB doesn't vary with fetal distress. Hence in addition to the standard BPP, a comprehensive evaluation of heart function and fetal circulation using Cardiovascular profile (CVP) score should be routinely performed in fetuses with CHB. CVP score, originally described by Huhta, ${ }^{8}$ is a 10 - point assessment of cardiac function and fetal circulation.

Management of NLE: In utero management with dexamethasone one (PRIDE study) ${ }^{9}$ or with IVIG(PITCH study ${ }^{10}$ may arrest the disease progression. Indications for pacemaker insertion in neonates with $\mathrm{CHB}$ include $\mathrm{HR}<55$ BPM in structurally normal heart or HR $<70$ BPM with concomitant CHD or signs of ventricular dysfunction.

\section{CONCLUSION:}

1. In case of persistent bradycardia not improving with resuscitation, CHB should be considered. 


\section{CASE REPORT}

2. Cutaneous, hepatic and hematological manifestations of NLE resolve without any long term sequelae and proper management of CCHB with pacemaker implantation determines the long term prognosis.

3. Ideal approach for CHB is prevention by targeting the therapy to eliminate antibodies before $\mathrm{AV}$ node destruction.

\section{REFERENCES:}

1. Michaelsson M, Engle MA CCHB: An international study of the natural history. Cardiovasc clin. 1972.

2. Chronister CS. Congenital complete atrioventricular block in a young man: a case study. Crit care Nurse. 2009; 29 (5): 45-56.

3. Buyon JP, Waltock J, Kleinman C, Copel J. In utero identification and therapy of congenital heart block. Lupus. 1995; 4: 116-21.

4. Friedman DM, Rupel A, Buyon JP. Epidemiology, etiology, detection and treatment of autoantibody-associated congenital heart block in neonatal lupus. Curr Rheumatol Rep. 2007; 9: 101-8

5. Lazzerini PE, Capecchi PL, Guideri F. Acampa M, Galeazzi M, LaghiPasini F. Connective tissue diseases and cardiac rhythm disorders: an overview. Autoimmun Rev. 2006; 5 (5): 306-13.

6. Guettrot-ImbertG, Cohen L, FermontL, Villain E, Frances C, Thiebau-georges O, e tal. A new presentation of neonatal Lupus: 5 cases of isolated mild endocardial fibroelastosis associated with maternal Anti-SS/Ro and Anti-SSB/La antibodies. Rheumatol.2011; 38(2): 378-86.

7. Kaaja R and Julkunen H (2003) Prevention of recurrence of congenital heart block with intravenous immunoglobulin and corticosteroid therapy: comment on the editorial by Buyon et al. (letter). Arthritis Rheum48: 281-282.

8. Huhta JC. Right ventricular function in the human fetus. JPerinat Med 2001; 29: 381-9

9. Preventive IVIG Therapy for Congenital Heart Block (PITCH) (http://clinicaltrials. gov/ct/show/NCT00460928?term=NCT00460928 \& rank=1)(accessed13 January2009).

10. Friedman DM et al. (2008) Utility of cardiac monitoring in foetuses at risk for CHB. PR Interval and Dexamethas one Evaluation PRIDE prospective study. Circulation 117: 485-493.

\section{ABBREVIATIONS:}

CCHB: Complete congenital heart block.

NLE: Neonatal Lupus Erythematous.

SLE: Systemic Lupus Erythematosus.

NRP: National Resuscitation Program.

BPM: Beats per Minute.

ANA: Anti neutrophillic antibodies. 


\section{CASE REPORT}

Figure 1: Wenkebach (Mobitz type 1) second degree heart block.

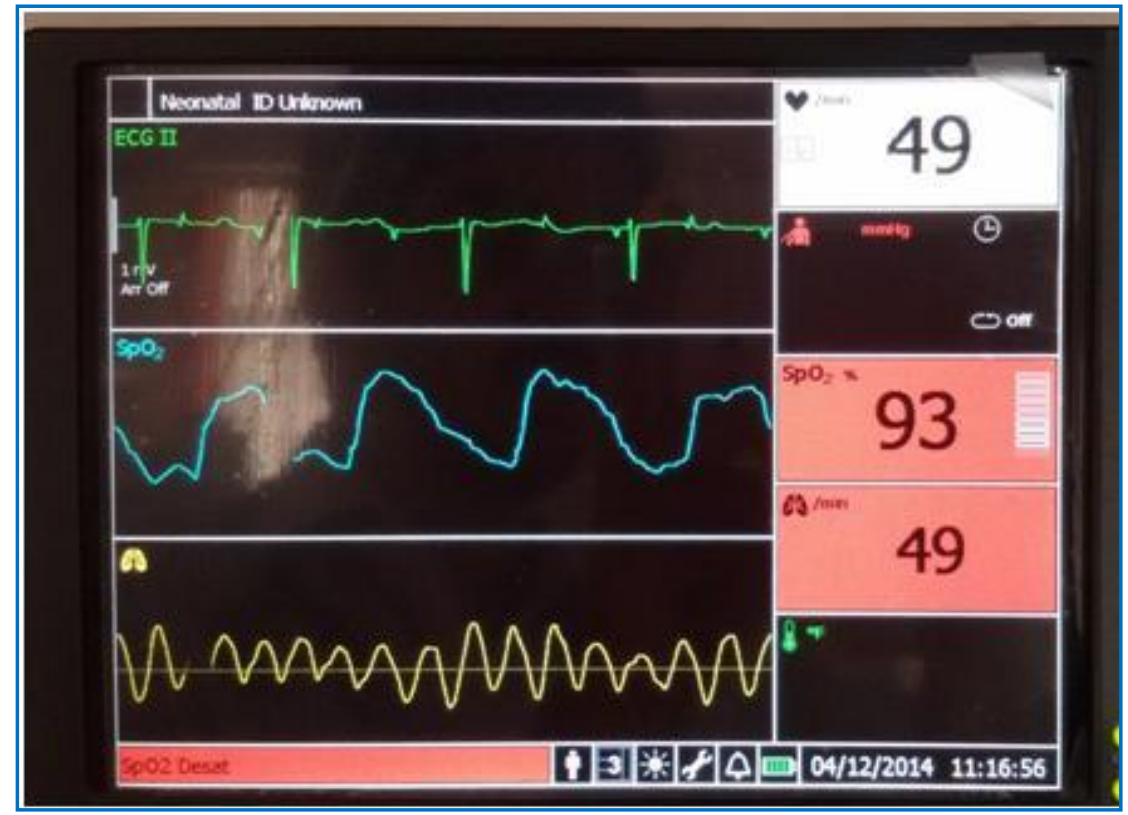

Figure 1

Figure 2: Third degree heart block showing AV dissociation.

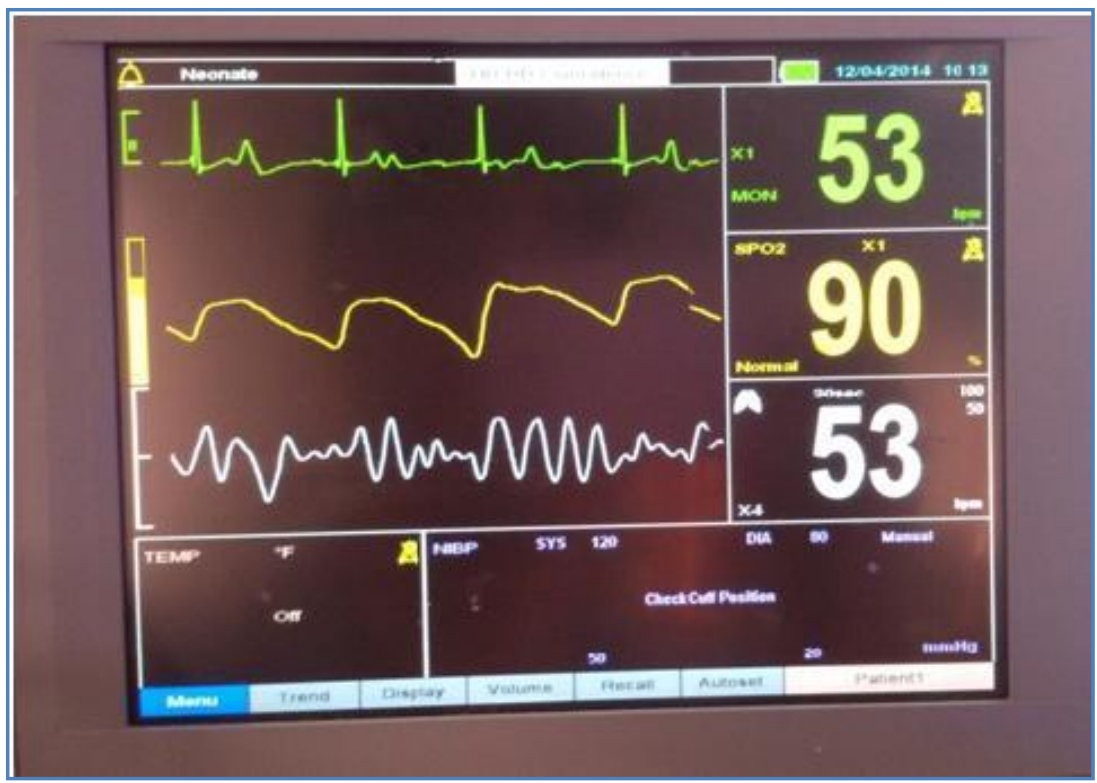

Figure 2 


\section{AUTHORS:}

1. D. Manikyamba

2. N. Madhavi

3. I. V. Padmavathi

4. A. Krishna Prasad

\section{PARTICULARS OF CONTRIBUTORS:}

1. Professor \& HOD, Department of Paediatrics, Rangaraya Medical College, Kakinada.

2. Associate Professor, Department of Paediatrics, Guntur Medical College, Guntur.

3. Post Graduate, Department of Paediatrics, Rangaraya Medical College, Kakinada.
4. Associate Professor, Department of Pediatrics, Rangaraya Medical College.

\section{NAME ADDRESS EMAIL ID OF CORRESPONDING AUTHOR:}

Dr. Manikyamba, Professor \& HOD, Department of Pediatrics, Government General Hospital, Kakinada, Andhra Pradesh, India.

E-mail: mani.jonnalagedda@gmail.com

Date of Submission: 08/01/2015.

Date of Peer Review: 09/01/2015.

Date of Acceptance: 30/01/2015.

Date of Publishing: 09/02/2015. 